\title{
Investigation of Motor Topologies for SMC Application
}

\author{
Yiping Dou ${ }^{1,2}$, Youguang $\mathrm{Guo}^{2}$, , Jianguo $\mathrm{Zhu}^{2}$ \\ ${ }^{1}$ Faculty of Electric Engineering and Automation, Nanjing Normal University, Nanjing 210042, China \\ ${ }^{2}$ Faculty of Engineering, University of Technology, Sydney, NSW 2007, Australia
}

\begin{abstract}
Soft magnetic composite (SMC) materials possess a number of unique properties and have undergone a significant development in the past decade. Based on the experiences on SMC materials and SMC electrical machines from our research group and other researchers, this paper reviews the investigation on motor topologies for SMC application. Both successful experiences and existing difficulties are analyzed and discussed. It is found that the application of SMC is preponderant in small permanent magnet motors with complex topologies and 3D magnetic flux. Possible further work required for commercial success of SMC machines is proposed.
\end{abstract}

\section{INTRODUCTION}

The major advantages of SMC include the isotropic magnetic and thermal behaviors, very low eddy current loss, relatively low total core loss at medium and higher frequencies, and easy fabrication with complex shape [1]. Therefore, SMC is very suitable for developing low cost high performance electrical machines.

Unfortunately SMC has some drawbacks as well, such as poor magnetic permeability, high magnetic hysteresis loss and low mechanical strength, compared with the traditional laminated steel. Attention should be paid in the design stage to avoid or reduce these negative effects. Arduous effort and encouraging achievement have been made by various researchers. In this paper, the investigation on motor topologies for the best use of $\mathrm{SMC}$ is reviewed and possible further work required for the commercial success of SMC machines is proposed.

\section{COMPARISON OF SMC AND LAMINATED STEEL FOR MOTOR APPLICATION}

\section{A. Production technique and cost}

By the use of the powder metallurgy technique, SMC parts require no subsequent treatment other than curing at a temperature of about $500^{\circ} \mathrm{C}$. In terms of production efficiency and material utilization, SMC and the powder metallurgical process offer major advantages over the traditional lamination technology. The mass production cost using this technology could be very low. The process by which the powder is produced itself is not high cost but production volume is very much smaller than sheet steel at present and so raw material costs are not yet competitive with cheap lamination steels. A move to use this material requires major changes in manufacturing processes for instance pressing rather than punching and stacking, new winding machines, changes in insulation systems and different assembly operations. The balance of cost will also change, for instance motors constructed from SMC so far tend to have less copper by taking advantage of design freedom to produce shorter end windings. It is clear that advantage will pass to the manufacturer who is willing to make necessary changes and the associated investment.

\section{B. Magnetic and thermal isotropy}

The isotropic magnetic and thermal characteristics of SMC opens up crucial design benefits compared with lamination steels in which flux is generally constrained to lie in 2D planes. SMC parts are compressed in a die to form complex net-shape components. This opens the way for new construction techniques, and previously unobtainable features such as embedded end windings can now easily be achieved. The SMC components can be made with smooth corners in crucial areas, for instance near contact areas with the windings and their associated insulation. Therefore the groundwall insulation can be thinner and more space is available for the windings.

Isotropic thermal behavior is also advantageous. The thermal conductivity of SMC is about $20 \mathrm{~W} /(\mathrm{m} \cdot \mathrm{K})$. This is similar to the conductivity in the plane of $3 \%$ silicon lamination steel, at around $25 \mathrm{~W} /(\mathrm{m} \cdot \mathrm{K})$ [2]. However, the thermal conductivity of lamination steel is more than an order of magnitude lower across the plane of the laminations, around 1.5 to $2 \mathrm{~W} /(\mathrm{m} \cdot \mathrm{K})$ under pressure or just $1 \mathrm{~W} /(\mathrm{m} \cdot \mathrm{K})$ with no pressure [2]. In most electrical machines this is not a problem because the heat is removed from the core back, with a radial heat flow within the plane of laminations. However, with SMC use, the heat from the end windings could flow directly into the core, reducing the end-winding cooling. Non-standard machine geometries can benefit even further from the 3D heat flow paths.

The isotropic magnetic characteristics are potentially far more important. The easiest machine types with which to justify this claim are the various forms of machines employing doubly salient and PM structures [3]. The most commonly accepted amongst these are hybrid stepping motors, but there are many new geometries at the prototype or development stage. A common feature of many of these machines is the fully $3 \mathrm{D}$ flux patterns; for instance the hybrid motor usually has axial magnet driven fields whose size is modulated by radial/circumferential derived reluctance variations. The losses associated with these axial field variations, occurring as they do normal to the plane of the laminations, have formerly limited the maximum stepping speed of these motors. These machines naturally require higher frequency for the same rotational speed but they (arguably) give the highest torque per unit volume of any machine. The potential for improvement using powder metallurgy is obvious. Conventional machine geometries can also potentially benefit; for instance the extra losses associated with skew can be eliminated and end region stray loss is also reduced. 


\section{Core Loss}

Because in bonded materials there is very little conduction between grains, the SMC material tends to have very low eddy currents until the skin depth becomes comparable with the size of the powder grains. The powder particle sizes of SMC are generally small, about $100 \mu \mathrm{m}$ [3]. This makes iron losses at high frequency operation relatively good. SMC materials open opportunities with high frequency operation to reduce the size of the machine for a given application. At low frequencies the total loss is dominated by hysteresis loss, which is higher than that of sintered products due to the deformation of particles during compacting. However, the use of heat treatment to achieve stress relief will reduce the hysteresis loss, but if the insulation layer disintegrates the eddy current loss increases. Total disintegration of the insulation layer will result in high eddy current loss, so despite a reduction in the hysteresis loss the total loss can be well above that achieved prior to heat treatment.

A continuous insulation layer, which withstands heat treatment, is not sufficient in itself to achieve low total loss. The thickness of the insulation layer must also be minimized and high density attained. The high hysteresis loss resulting from strain and poor domain structure means high losses at low frequencies, for instance $1.5 \mathrm{~T}$ at $50 \mathrm{~Hz}$ gives around $15 \mathrm{~W} / \mathrm{kg}$ (for SOMALOY ${ }^{\mathrm{TM}} 500$ ), compared to $3 \mathrm{~W} / \mathrm{kg}$ for good motor laminations [3].

\section{Permeability}

The unsaturated relative permeability of SMC material is not high. Typical values are in the range 200 to 600 . This is a particular problem in small machines with armature excitation such as induction and reluctance (switched and synchronous) motors since the magnetizing current is relatively large. But it is not serious in wound field machines, such as DC and AC commutator and synchronous machines, and it is usually negligible in PM machines, whose magnetic circuit is dominated by the large effective air gap presented by the magnet. The new possibilities offered by the production of the core offer an opportunity to overcome this problem without increasing the outside dimensions of the machine, but only at the expense of the use of lower no-load flux densities and larger core volumes. It is unlikely that powder materials can achieve anywhere near the maximum permeability of lamination steels which are typically greater than 8000 . It is also unlikely that the unsaturated relative permeability will improve much with further development.

\section{E. Saturation flux density}

The saturation flux density is lower than that of the base iron powder. This is a difficult figure to quote as a single number because the porosity resulting from less than full density implies a distributed air gap and hence the B-H curve rolls away much more slowly than normal steels.

\section{F. Mechanical Strength}

Bonding the powder inevitably makes the material rather weak especially when high density is sought. Typical figures are 10-20 $\mathrm{MPa}$ in tension. This is high enough to withstand magnetic forces but care must be exercised with mechanically induced forces, for instance thermal expansion and rotation. As to the binder, its nature makes the material brittle and shock load is of concern. The porosity in the material is unavoidable and needs consideration in respect of corrosion protection [3].

Nowadays, electrical micromotors and low power motors are widely used in automation, robotics, office and home apparatus. In general, their core structure and the magnetic flux path are very complex and construction by lamination steels is very difficult, and sometimes impossible. Solid steels suffer excessive eddy current losses. The powder composites can be produced at a very high rate, providing an obvious economic advantage. Furthermore, it reveals design freedom, a key benefit, for motor designers because the powdered nature means magnetic and thermal isotropy and many constraints imposed by electrical steels are avoided.

Some design points are listed in Table I for comparing the pros and cons of SMC and laminated steel.

TABLE I

COMPARISON OF SMC AND LAMINATED STEEL

\begin{tabular}{|l|l|l|}
\hline Performance & SMC & Laminated steel \\
\hline $\begin{array}{l}\text { Design } \\
\text { flexibility }\end{array}$ & $\begin{array}{l}++3 \mathrm{D} \text { flux (e.g. claw pole } \\
\text { motors, TFM, vertical } \\
\text { motor, etc.) with complex } \\
\text { structure. }\end{array}$ & $\begin{array}{l}\text { - 2D flux (flux must be } \\
\text { within the lamination } \\
\text { plane to avoid excessive } \\
\text { eddy current). }\end{array}$ \\
\hline Material waste & $\begin{array}{l}\text { ++ Net-shape compaction } \\
\text { with minimum further } \\
\text { machining. }\end{array}$ & $\begin{array}{l}\text {-- Material waste when } \\
\text { punching. }\end{array}$ \\
\hline Manufacturing & $\begin{array}{l}\text { ++ Prospect of easy } \\
\text { manufacturing, so low cost. }\end{array}$ & $\begin{array}{l}\text {-- Impossible for some } \\
\text { types of machines. }\end{array}$ \\
\hline
\end{tabular}

\section{Motor TOPOLOGIES INVESTIGATED}

Earlier attempts of using SMC in motor construction started in 1980's [4], but due to various reasons the motor performance was far from satisfactory. In 1992, Jansson reported the product process and properties of SMC materials for AC applications [5]. Since then, investigation on development of SMC materials and their application in electrical machines have intensified and encouraging progress has been achieved [1]. Some typical motor topologies were picked up here from various types of SMC motors designed and manufactured by different researchers.

\section{A. Claw Pole Machines}

Electrical machines with claw pole rotors are well known and have been produced in high volumes for many years. A typical application is the almost universal use in car alternators. The claw pole armature structure is also known, but it is very hard to use laminations for construction of the claw pole armature. A solid armature would suffer too large eddy current loss unless the machine is very small or the speed is very low.

Since 1996, the research group of the Newcastle University, UK, in collaboration with Höganäs AB, Sweden, has studied various types of SMC motors for different applications, one of which is a claw pole motor with SMC stator core [6]. The prototype machine has complex 3D electromagnetic field, high frequency and unusual construction with 24 poles, outside diameter of $200 \mathrm{~mm}$, and bore of $117 \mathrm{~mm}$. The rated current is $17 \mathrm{~A} \mathrm{rms}$ (naturally cooled, no fan) and the average torque per unit active mass is about $3.3 \mathrm{Nm} / \mathrm{kg}$. With $\mathrm{NdFeB}$ magnets and improved cooling, this would be substantially increased. 
In 2001, Cros et al. reported their study of an SMC universal motor [7]. The stator used the claw pole structure and the magnetic circuits of both the stator and rotor were made of SMC materials (Atomet EM1). The use of SMC in universal motors can reduce the manufacturing cost, but the benefit becomes less significant as far as efficiency is concerned.

In 2004, Ronghai Qu et al. from GE Company proposed a novel split-phase, claw pole, induction machine (IM) [8]. SMC material is used in the stator cores. It is found that the $200 \mathrm{~W}$ prototype has comparable material cost to the normal IM with higher efficiency and much higher torque density.

In 1998, the research team at University of Technology, Sydney (UTS), started its research on development of low cost PM motors using new SMC materials, in collaboration with Höganäs AB. With the special strength in magnetic testing and modeling, the team firstly carried out a comprehensive study of the magnetic properties of SMC materials. The magnetic properties of SOMALOY ${ }^{\mathrm{TM}} 500$ have been measured under alternating, 2D and 3D rotating magnetic excitations [9-10]. The team led the design and construction of a single-phase claw pole PM SMC motor, and a three-phase claw pole PM SMC motor [11]. The rated power of the three-phase prototype is $500 \mathrm{~W}$ at $1800 \mathrm{rpm}$ with a specific torque of $2.8 \mathrm{kNm} / \mathrm{m}^{3}$ and an efficiency of $81 \%$.

\section{B. Transverse Flux Machines}

Transverse flux machines are very close cousins to claw pole armature machines, sharing their reasons for high specific output. The use of SMC in transverse flux geometry was first attempted in 1996 by Mecrow et al., who designed a 3-phase 3-stack transverse flux motor (TFM) with a novel structure using SMC core [12]. It can achieve very high specific torque due to high operating frequency (the machines have 100 poles). Considering that each stack forms a phase and is magnetically independent from the others, a single-phase prototype was constructed. The major dimensions of the TFM prototype include: stator outside diameter of $362 \mathrm{~mm}$, overall axial length of $60 \mathrm{~mm}$, rotor outside diameter of $300 \mathrm{~mm}$ and main (axial) airgap length of $0.5 \mathrm{~mm}$. Some results have been obtained from the test on the prototype, such as a specific torque of 12.35 $\mathrm{Nm} / \mathrm{kg}$ (active mass).

The team in UTS also developed a three-phase transverse flux PM SMC motor [13]. The motor has an outer rotor comprising a mild steel cylinder with two arrays of magnets per phase mounted on the inner surface. The three phases of the motor are stacked axially with an angular shift of $120^{\circ}$ electrical from each other. The transverse flux prototype reached a maximum efficiency of $79.5 \%$ at the rated power $(640 \mathrm{~W})$ and speed $(1800$ $\mathrm{rpm}$ ), although the rotor yoke was, for simplicity of manufacture, made of mild steel. The eddy current loss in the mild steel reduced the overall efficiency by about $6 \%$. The volume of the three phase transverse flux motor is only half of that of an induction motor of the same power rating.

\section{Axial Field Machines}

Axial field machines have found a rapid application and development in the past few decades due to its high specific torque and compact topology.
In 1997, Zhang et al. developed an axial flux PM brushless DC motor using SMC ABM100.32 supplied by Höganäs AB, and achieved a maximum efficiency of $68 \%$ [14]. The major dimensions include outer radius of $40 \mathrm{~mm}$, inner radius of 25 $\mathrm{mm}$, stator axial length of $20 \mathrm{~mm}$, rotor axial length of $10 \mathrm{~mm}$, and airgap length of $1 \mathrm{~mm}$. The SMC prototype has 6 poles and is designed to operate at a rated speed of $2500 \mathrm{rpm}$, implying an operating frequency of $125 \mathrm{~Hz}$. In 1998, they reported another axial flux motor with interior PM rotor made of SMC [15].

In 2005, Chen and Pillay presented the potential application of SMC material in low speed, directly driven, axial-flux PM wind generators [16]. The prototype with double rotor, axial-flux, and slotted structure was carefully designed and tested to employ the advantages of SMC materials such as better performance, reduced size and weight.

In 2002, Cvetkovski et al. presented the design of a PM disk motor by using SMC material. The motor is a double-sided axial field motor with two stators and a centered PM rotor [17].

\section{Others}

In 2005, Nord et al. proposed a vertical motor design, Powder $\mathrm{Keg}^{\mathrm{TM}}$, which employs a very different physical architecture compared to a standard electrical machine [18]. The stator poles are parallel to the motor shaft. The rotor and rotor magnets are located to interact radially with the stator poles. Two prototype motors, using different SMC materials, have been simulated, built and tested to show how material properties affect the motor performance.

In 2006, Kim presented a new type SMC universal motor [19]. The stator is made by combination of the SMC pole and the silicon steel yoke, considering SMC's mechanical merit and electromagnetic demerit. It's believed that by the proper 3D shape design of SMC pole, the proposed motor is expected to have an advantage of $9 \%$ coil saving with the same torque as the conventional motor.

Till now, SMC machines have also been commercially used in ABS brake system, electric vehicle and other servo systems by companies like Aisin Seiki in Japan, Phase Motion Control in Italy and Smart Motor in Norway [1].

Based on a comprehensive analysis of many references, the motor topologies for SMC application with the pros are listed in Table II. The cons should be also considered, mainly due to the low permeability of SMC which causes flux leakage and low power factor. Molding cost is expected to be very low, but this actually needs more investigation.

TABLE II

MOTOR TOPOLOGIES INVESTIGATED

\begin{tabular}{|l|l|}
\hline $\begin{array}{l}\text { Motor } \\
\text { topologies } \\
\text { (types) }\end{array}$ & Pros for SMC application \\
\hline $\begin{array}{l}\text { PM claw pole } \\
\text { motor }\end{array}$ & $\begin{array}{l}\text { 3-D flux; Torque density can be high; Easy manufacturing } \\
\text { (almost impossible to use sheet steels). }\end{array}$ \\
\hline $\begin{array}{l}\text { PM transverse } \\
\text { flux Motor }\end{array}$ & As above. \\
\hline $\begin{array}{l}\text { Axial field PM } \\
\text { machine }\end{array}$ & Avoiding the spiral laminated steel \\
\hline $\begin{array}{l}\text { Radial field } \\
\text { PM machine }\end{array}$ & $\begin{array}{l}\text { Stator tooth can be longer than the rotor PM axially and } \\
\text { circumferentially to obtain higher specific torque. }\end{array}$ \\
\hline $\begin{array}{l}\text { Universal } \\
\text { motor }\end{array}$ & $\begin{array}{l}\text { Can use complex structure to increase the specific torque, } \\
\text { e.g. claw pole structure for the stator. }\end{array}$ \\
\hline
\end{tabular}




\section{CONCLUSION AND FURTHER WORK}

To best use the unique properties of SMC, motor topologies are crucial. This paper aims to find appropriate motor structures for SMC application based on an extensive survey of SMC materials and existing SMC machines. To investigate the potential of SMC materials the in manufacture of small motors of complex structures, various types of motors with SMC core have been designed and manufactured by different researchers. The performance of the prototypes is comparable to that of similar motors with electrical steel cores at potentially reduced manufacturing cost. The motor design method and performance analysis have been validated by experiments on the prototypes.

In spite of the encouraging progress, a large amount of work is still required for the ultimate commercial success. The following further work should be considered and implemented:

1) Innovative structure is needed, probably complex but can be compacted in a die.

2) Small cores can be pressed once. The problem with assembly cost and difficulty is solved.

3) Redistribute the core loss and copper loss, e.g. 50\% for each. This can achieve the highest efficiency theoretically.

4) The magnetic properties of SMC under 3D magnetic field excitations need to be investigated for 3D flux motors.

5) Develop low cost inverters and sensorless control algorithms considering that the SMC motor usually uses a simple concentrated winding.

6) Find an optimum SMC composition for the best compromise between the magnetic and mechanical properties.

\section{REFERENCES}

[1] "The latest development in soft magnetic composite technology," $S M C$ Update, Reports of Höganäs AB, Sweden, 1997-2007. Available at http://www.hoganas.com/, see News then SMC Update.

[2] T. J. Roberts, "Determination of the thermal constants of the heat flow equations of electrical machines," in Proceedings of Institute of Mechanical Engineering, Vol. 184, 1964-1970, p. 84.

[3] A. G. Jack, "Experience with the use of soft magnetic composites in electrical machines," in Proc. Int. Conf. on Electrical Machines, Istanbul, Turkey, Sept. 1998, pp. 1441-1448.

[4] S. Kubzdela and B. Weglinski, "Magnetodielectrics in induction motors with disk rotor," IEEE Trans. Magn., Vol. 24, No. 1, pp. 635-638, Jan. 1988 .
[5] P. Jansson, "Soft magnetic materials for AC applications," Powder Metallurgy, Vol. 35, No. 1, pp. 63-66, 1992

[6] A. G. Jack, B. C. Mecrow, C. P. Maddison, and N. A. Wahab, "Claw pole armature permanent magnet machines exploiting soft iron powder metallurgy," in Proc IEEE Int. Conf. on Electric Machines and Drives, Milwaukee, USA, May 1997, pp. MA1/5.1-5.3.

[7] J. Cros, P. Viarouge, Y. Chalifour, and J. Figueroa, "A new structure of universal motor using soft magnetic composites," IEEE Trans. Industry Applications, Vol. 40, No. 2, pp. 550-557, Mar./Apr., 2004.

[8] R. Qu, G. B. Kliman, and R. Carl, "Split-phase claw-pole induction machines with soft magnetic composite cores," in Proc. IEEE Industry Applications Society Annual Meeting, Vol. 4, Oct. 2004, pp. 2514-2519.

[9] Y. G. Guo, J. G. Zhu, and J. J. Zhong, "Measurement and modeling of magnetic properties of soft magnetic composite materials under 2D vector magnetizations," Journal of Magnetism and Magnetic Materials, Vol. 302, No. 1, pp. 14-19, 2006

[10] Y. G. Guo, J. G. Zhu, Z. W. Lin, and J. J. Zhong, "Measurement and modeling of core losses of soft magnetic composites under 3D magnetic excitations in rotating motors," IEEE Trans. Magn., Vol. 41, No. 10, pp. 3925-3927, 2005.

[11] Y. G. Guo, J. G. Zhu, P. A. Watterson, and W. Wu, "Development of a claw pole permanent magnet motor with soft magnetic composite stator," Australian Journal of Electrical \& Electronic Engineering, Vol. 2, No. 1, pp. 21-30, 2005 .

[12] B. C. Mecrow, A. G. Jack, and C. P. Maddison, "Permanent magnet machines for high torque, low speed applications," in Proc. Int. Conf. on Electrical Machines, Vigo, Spain, Sept. 1996, pp. 461-466.

[13] Y. G. Guo, J. G. Zhu, P. A. Watterson, and W. Wu, "Development of a PM transverse flux motor with soft magnetic composite core," IEEE Trans. Energy Conversion, Vol. 21, No. 2, pp. 426-434, June 2006.

[14] Z. Zhang, F. Profumo, A. Tenconi, and M. Santamaria, "Analysis and experimental validation of performance for an axial flux permanent magnet brushless DC motor with powder iron metallurgy cores," IEEE Trans. Magn., Vol. 33, No. 5, pp. 4194- 4196, Sept. 1997.

[15] F. Profumo, A. Tenconi, Z. Zhang, and A. Cavagnino, "Novel axial flux interior PM synchronous motor realized with powdered soft magnetic materials," in Proc. IEEE Industry Application Society Annual Meeting, St. Louis, USA, Oct. 1998, pp. 152-158

[16] Y. Chen and P. Pillay, "Axial-flux PM wind generator with a soft magnetic composite core," in Proc. IEEE Industry Applications Society Annual Meeting, Hong Kong, China, Oct. 2005, Vol. 1, pp. 231-237.

[17] G. Cvetkovski, L. Petkovska, M. Cundev, and S. Gair, "Improved design of a novel PM disk motor by using soft magnetic composite material," IEEE Trans. Magn., Vol. 38, No. 5, pp. 3165-3167, Sept. 2002.

[18] G. Nord, P. Jansson, C. C. Petersen, and T Yamada, "Vertical electrical motor using soft magnetic composites," in Proc. IEEE Int. Conf. on Electric Machines and Drives, May 2005, pp. 373-377.

[19] B.-T. Kim, "Design of new type universal motor using soft magnetic composites," Journal of Electrical Engineering \& Technology, Vol. 1, No. 2, pp. 211-215, 2006. 